\title{
Clinical Studies of Dental Cements: V. Recall Evaluation of Restorations Cemented with a Zinc Oxide-Eugenol Cement and a Zinc Phosphate Cement
}

\author{
RALPH G. SILVEY and GEORGE E. MYERS \\ Crown and Bridge Department, School of Dentistry, The University of Michigan, \\ Ann Arbor, Michigan 48104, USA
}

\begin{abstract}
Patients with restorations cemented with a reinforced zinc oxide-eugenol cement and a zinc phosphate cement were recalled after a four- to seven-year interval. No significant differences in clinical success were observed between restorations luted with the two cements. No significant difference in the incidence of caries at the restoration margins was noted between the cements.
\end{abstract}

A previous article ${ }^{1}$ presented data, collected during a two-year period, of restorations comprising both single crowns and bridges cemented with a zinc oxide-eugenol cement that had a compressive strength of 8,000 to 9,200 psi.a $^{\text {a }}$ Successful retention of the restorations was obtained during the two-year period in $94.4 \%$ of single restorations and $93.6 \%$ of the bridge retainers. This report presents data collected at a later date from the same group of patients and restorations, and gives information on the survival of the restorations during a six- to seven-year period. In addition, data not available at the time the previous article was written, are given for a group of patients in whom restorations were cemented with zinc phosphate cement $^{b}$ and recalled after a four-year interval.

\section{Materials and Methods}

Patients from the previous study were recalled and examined for loose restorations, using the techniques already described. ${ }^{1}$ Records were scrutinized for information on re-

This investigation was supported, in part, by $\mathrm{Na}$ tional Institutes of Health Project DE 02593-03.

Received for publication November 13, 1974

Accepted for publication July 25, 1975.

- Fynal cement, L. D. Caulk Co., York, Pa.

b Tenacin, L. D. Caulk Co., York, Pa. cementations that might have been done in the interim period, and the patient was asked if any restorations had been recemented. In addition, all the margins of the restorations were examined visually with a sharp explorer for the presence of caries. When up-to-date radiographs were available, they were examined; and in cases where radiographs were deemed necessary to resolve the question, they were taken. The research records of the cases contained data on the types of retainers and their retentive quality. The total number of patients who participated in the study was 605 . The number of patients who were able to return on recall was 159. Those cases cemented with zinc oxide-eugenol cement were in the sixth to seventh year of observation. Those cases cemented with zinc phosphate were in the fourth year of observation. Cases recalled in this study which had failed in the two-year recall ${ }^{1}$ were included as failures in this recall.

\section{Results}

A total of 109 bridges in 99 patients were cemented with zinc oxide-eugenol cement and examined. Of these bridges, 18 had a history of one or more retainers becoming loose. There were 265 retainers in the bridges and of these retainers, 24 came loose.

A total of 28 single crown restorations in 20 patients cemented with zinc oxide-eugenol cement were examined; none had loosened.

In 69 patients, 78 bridges cemented with zinc phosphate cement were examined; five bridges in four patients had a history of coming loose. Of the 178 retainers in the 78 bridges, 7 retainers had laosened.

In 18 patients, 31 crowns cemented with 
TABLE 1

Zinc OXide-Eugenol Cement Recall Data for a SiX- To SEVEN-YEAR INTERVAL

\begin{tabular}{lccccc}
\hline $\begin{array}{l}\text { Bridge Retainer } \\
\text { Type }\end{array}$ & $\begin{array}{c}\text { Total in } \\
\text { Studies }\end{array}$ & Successful & Failed & Caries & $\%$ Success \\
\hline Complete crown & 83 & 77 & 6 & 10 & $92.7 \%$ \\
3/4 Crown & 121 & 109 & 12 & 5 & $90.1 \%$ \\
MOD. P.C. & 31 & 26 & 5 & 0 & $83.8 \%$ \\
Pinledge & 30 & 29 & 1 & 0 & $96.7 \%$ \\
\hline
\end{tabular}

zinc phosphate cement were examined; two crowns had loosened.

Caries was found in 15 of a total of 265 bridge retainers cemented with zinc oxideeugenol cement and in 6 of a total of 178 bridge retainers cemented with zinc phosphate cement. In the instance of zinc oxideeugenol cement, 11 carious lesions occurred in 10 of 99 patients. In the case of the zinc phosphate cement, 6 carious lesions occurred in 6 of the 69 patients. No carious lesions occurred in the crown cases with either cement.

\section{Discussion}

It should be noted that the data for the zinc oxide-eugenol cement were accumulated during a six- to seven-year period. The data for the zinc phosphate cement were accumulated during a four-year period. Previous studies during a two-year period with zinc oxide-eugenol cements have shown that a high percentage of failures occur in the first nine months subsequent to cementation.

The percentage of success of the 109 bridges cemented with the zinc oxideeugenol cement was $83.5 \%$. The percentage of success of 78 bridges cemented with zinc phosphate cement was $93.6 \%$.

Each bridge involves two or more retainers. A bridge failure as recorded in this study may be caused by the failure of one or more retainers. A bridge failure may therefore represent one cement failure in two or more retainers. It is perhaps more meaningful in terms of the success of the cement to examine the number of retainer successes as compared to the total number of retainers luted with each cement.

The percentage of retainers successfully cemented with the zinc oxide-eugenol cement was $90.9 \%$. The value obtained after two years in the previous study was $93.6 \%$. The percentage of retainers successfully cemented with the zinc phosphate cement was $96.06 \%$. No values for this cement were available in the previous study.

The percentage of success of the 28 crowns cemented with zinc oxide-eugenol was $100 \%$. The percentage of success of 31 crowns cemented with zinc phosphate cement was $93.5 \%$.

Table 1 gives an analysis of the retainers cemented with zinc oxide-eugenol cement. Table 2 gives an analysis of retainers cemented with zinc phosphate cement.

The incidence of caries in the retainers cemented with zinc phosphate cement was $3.4 \%$ of the sample. The comparable figure for the retainers cemented with zinc oxideeugenol cement was $5.66 \%$. It is not thought that any conclusions can be drawn regarding the relative merits, so far as retention is concerned, of the several types of retainers listed in the table. What does become clear from clinical observation is that any type of retainer that does not meet the requirements of retention will fail no matter what cement is used. The variation in the success rates between retainers and between cements is

TABLE 2

Zinc Phosphate Cement Recall Data for a four-Year Interval

\begin{tabular}{lccccc}
\hline $\begin{array}{l}\text { Bridge Retainer } \\
\text { Type }\end{array}$ & $\begin{array}{c}\text { Total in } \\
\text { Study }\end{array}$ & Successful & Failed & Caries & $\%$ Success \\
\hline Complete crown & 50 & 49 & 1 & 5 & $98 \%$ \\
3/4 Crown & 87 & 84 & 3 & 1 & $96.5 \%$ \\
MOD. P.C. & 25 & 23 & 2 & 0 & $92 \%$ \\
Pinledge & 16 & 15 & 1 & 0 & $93.7 \%$ \\
\hline
\end{tabular}


more a comment on the retentive quality of the particular retainers than either the type of retainer or the cement.

\section{Conclusions}

No significant difference in clinical success was noted between the zinc oxide-eugenol cement and the zinc phosphate cement.

No significant difference was detected in the effectiveness of the several types of bridge retainers.
No significant difference in the incidence of caries on abutment teeth was detected between the two cements.

The authors acknowledge Dorothee Hansen for valuable assistance in recording and analyzing the data collected in this study.

\section{Reference}

1. GILSON, T.D., and MYERs, G.E.: Clinical Studies of Dental Cements: IV. A Preliminary Study of a Zinc Oxide-Eugenol Cement For Final Cementation, J Dent Res 49: 14-20, 1970. 